Personalidade Acadêmica Homenageada:

Florisbal de Souza Del'Olmo (Professor Convidado - UNICURITIBA)

\title{
LICENÇA MATERNIDADE NAS RELAÇÕES HOMOAFETIVAS: UM OLHAR SOB O PRINCÍPIO DA ISONOMIA MATERIAL
}

\section{VALMIR CÉSAR POZZETTI}

Doutor em Biodireito/Direito Ambiental pela Université de Limoges/França (título reconhecido pela Univ. Federal de Pernambuco). Mestre em Direito do Urbanismo e do Meio Ambiente, pela Université de Limoges, França (título reconhecido pela Universidade Luterana do Brasil). Bacharel em Direito pelo Centro Integrado de Ensino Superior da Amazônia/AM, Bacharel em Ciências Contábeis pela Faculdade São Luis/SP. Foi Conselheiro Estadual da OAB/AM no triênio 2016/2018. É Acadêmico Imortal da Academia de Ciências Contábeis do Amazonas. É Professor Adjunto da UFAM - Universidade Federal do Amazonas, ministrando disciplinas na graduação, no mestrado e Doutorado em Ciências Ambientais. É Professor Adjunto da UEA - Universidade do Estado do Amazonas, ministrando disciplinas na graduação e no Mestrado em Direito Ambiental. É professor de Módulos de Curta duração da Escola da Magistratura do Amazonas - ESMAM, onde ministra a disciplinas Direito Agrário nos Cursos de Formação de Magistrados. Possui aprovação em Concurso Público para professor: - da UNIFAP - Univ. Federal do Amapá; da UFRR - Univ. Federal de Roraima; da UFAM - Univ. Federal do Amazonas, da UEA - Univ. do Estado do Amazonas. Tem experiência na área de Direito e Ciências Contábeis, com ênfase em Direito Ambiental, Direito Tributário, Direito do Trabalho, Direito Agrário, Biodireito e Direito Urbanístico, atuando principalmente no tema "Biossegurança, Sustentabilidade e Preservação do Meio Ambiente".

\section{KALEEN SOUSA LEITE}

Especializada em Direito e Processo do Trabalho, graduação em Direito pela Universidade do Estado do Amazonas (2011) e graduação em Tecnologia e Criação 
Personalidade Acadêmica Homenageada:

Florisbal de Souza Del'Olmo (Professor Convidado - UNICURITIBA)

em Produção Publicitária pelo Instituto Federal de Educação, Ciência e Tecnologia do Amazonas (2006). Atualmente é técnico judiciário - Tribunal Regional do Trabalho da 11aㅡ Região (AM). Tem experiência na área de Direito do Trabalho e Comunicação Social.

\section{OBJETIVOS}

A presente pesquisa busca analisar o duplo direito à licença maternidade nas relações homoafetivas entre mulheres que se identificam pelo gênero feminino e se reconhecem como mães.

A Constituição Federal de $1.988 \mathrm{em}$ seu art. $7^{7^{1}}$, estabelece 0 direito à licença maternidade; entretanto, a Lei o 8.213/1991, que dispõe sobre os benefícios da Previdência Social, veda no art. 71-A, $\S 2^{0^{2}}$ a concessão da licença maternidade a mais de um segurado/segurada.

Nesse sentido, a presente pesquisa visa superar a vedação legislativa aplicando à norma, uma interpretação integrativa ao ordenamento jurídico sob viés da isonomia material, aplicando à temática os preceitos constitucionais da dignidade da pessoa humana (art. 1ํㅡㄹ III), proteção da família (art. 226) e vedação a atos de discriminação de qualquer espécie (art. 5oㅡ, caput).

Tal interpretação tem por importância garantir à mulher, independentente da orientação sexual, o exercício de direitos que lhe assiste, sob pena de transformar o Estado Democrático de Direito (art. 10, caput, CF/88) em um instrumento de exclusão social.

\footnotetext{
${ }^{1}$ BRASIL, Constituição da República Federativa do. Congresso Nacional, Brasília, 1988.

${ }^{2}$ BRASIL. Lei no 8.213/91. Benefícios da Previdência social, Congresso Nacional, Brasília, 1.991. Art Art. 71-A. Ao segurado ou segurada da Previdência Social que adotar ou obtiver guarda judicial para fins de adoção de criança é devido salário-maternidade pelo período de 120 (cento e vinte) dias. (...) omissis $\S 20$ Ressalvado o pagamento do salário-maternidade à mãe biológica e o disposto no art. 71-B, não poderá ser concedido o benefício a mais de um segurado, decorrente do mesmo processo de adoção ou guarda, ainda que os cônjuges ou companheiros estejam submetidos a Regime Próprio de Previdência Social.
} 
Personalidade Acadêmica Homenageada:

Florisbal de Souza Del'Olmo (Professor Convidado - UNICURITIBA)

\section{METODOLOGIA UTILIZADA}

Para a presente pesquisa utilizou-se o método dedutivo, processo pelo qual, com base em enunciados ou premissas, busca-se retirar uma verdade particular de um universo amplo.

Do ponto de vista dos procedimentos técnicos adotados, a pesquisa foi doutrinária e bibliográfica. Portanto, os materiais utilizados foram livros, periódicos, artigos científicos, teses de doutoramento e dissertações disponíveis na internet. Além de consulta à jurisprudência e a legislações pátrias e internacionais.

\section{REVISÃO DE LITERATURA}

O direito à licença maternidade foi estabelecido na Carta Magna de 1988 como direito fundamental, estabelecendo às mães licença remunerada com duração de 120 dias (art. $\left.7^{\circ}, \mathrm{XVIII}\right)^{3}$, sendo estabelecido ainda no art. 201, inciso II ${ }^{4}$, proteção à maternidade, especialmente à gestante.

A licença maternidade é compreendida atualmente como direitos humanos sociais, em consonância com os tratados e convenções internacionais de proteção à mulher trabalhadora e especialmente à criança, dos quais o Brasil é signatário-Pacto de San José da Costa Rica e Convenção Internacional sobre os direitos da criança 198 - ratificada pelo Brasil em 1990.

$\mathrm{Na}$ visão de Manoel Gonçalves Ferreira Filho, as referidas medidas protetivas atendem a duas finalidades: "por um lado, protege o trabalho da mulher, enquanto por outro atende a um elevado objetivo social, qual seja a defesa da família e da maternidade. ${ }^{5}$

\footnotetext{
${ }^{3}$ BRASIL, Constituição da República Federativa do. Congresso Nacional, Brasília, 1988.Art Art. 7º, CF/88: [...] XVIII - licença à gestante, sem prejuízo do emprego e do salário, com a duração de cento e vinte dias;

${ }_{5}^{4}$ Art. 201, CF/88: [...] II - proteção à maternidade, especialmente à gestante

${ }^{5}$ FERREIRA Fo, Manoel Gonçalves. In Comentários à Constituição Brasileira de 1988, Vol. 1, ed. Saraiva, 1990 , p. 100
} 
Personalidade Acadêmica Homenageada:

Florisbal de Souza Del'Olmo (Professor Convidado - UNICURITIBA)

A concepção de família, ao longo do tempo, vem apresentando novas construções sociais que merecem receber mesmo valor social atribuído ao modelo tradicional. Inicialmente o ordenamento jurídico apenas reconhecia como núcleo familiar a união entre homens e mulheres (art. 226, §3ำ, CF/88) ${ }^{6}$, devendo a lei facilitar a união Estável em casamento. Em 2011, após o julgamento da ADI no 4.277 proferido pelo Corte Suprema, com efeito erga omnes, o ordenamento jurídico brasileiro reconheceu à união homoafetiva o caráter de entidade familiar. Sob viés da isonomia, o relator Aires Brito ${ }^{7}$ defendeu que, tantos os casais heterossexuais como os homossexuais detêm o direito subjetivo de formação autônoma de família:

\begin{abstract}
Assim interpretando por forma não-reducionista o conceito de família, penso que este STF fará o que lhe compete: manter a Constituição na posse do seu fundamental atributo da coerência, pois o conceito contrário implicaria forçar o nosso Magno Texto a incorrer, ele mesmo, em discurso indisfarçavelmente preconceituoso ou homofóbico. Quando o certo - data vênia de opinião divergente - é extrair do sistema de comandos da Constituição os encadeados juízos que precedentemente verbalizamos, agora arrematados com a proposição de que a isonomia entre casais heteroafetivos e pares homoafetivos somente ganha plenitude de sentido se desembocar no igual direito subjetivo à formação de uma autonomizada família. Entendida esta, no âmbito das duas tipologias de sujeitos jurídicos, como um núcleo doméstico independente de qualquer outro e constituído, em regra, com as mesmas notas factuais da visibilidade, continuidade e durabilidade. Pena de se consagrar uma liberdade homoafetiva pela metade ou condenada a encontros tão ocasionais quanto clandestinos ou igualmente. $O$ arcabouço jurídico tem por fundamento garantir a mulher a proteção do bem da vida e subterrâneos. (...) (STF, ADI no 4.277/DF, Relator Ministro AYRES BRITO, DJE 5/5/2011) (gn)
\end{abstract}

Dessa forma, diante do reconhecimento de novas formações familiares, cabe ao ordenamento jurídico pátrio estender, a todos esses núcleos familiares, as garantias necessárias à proteção à família, conforme dispõe o art. 226 da $\mathrm{CF} / 88^{8}$.

\footnotetext{
${ }^{6}$ BRASIL, Constituição da República Federativa do. Congresso Nacional, Brasília, 1988.

7 BRASIL, STF - SUPREMO TRIBUNAL FEDERAL. ADI nํ 4.277/DF, Relator Ministro AYRES BRITO, DJE 05/05/2011.

${ }^{8}$ BRASIL, Constituição da República Federativa do. Congresso Nacional, Brasília, 1988.
} 
Personalidade Acadêmica Homenageada:

Florisbal de Souza Del'Olmo (Professor Convidado - UNICURITIBA)

Nessa perspectiva, a licença maternidade torna-se instrumento de proteção ao núcleo familiar, pois constitui auxílio à criança e à mãe nos primeiros meses de convivência para formação do singular vínculo sócio afetivo entre mãe e filho.

Aplicar tal proteção nas relações homoafetivas entre mulheres é conferir a ambas o direito à licença maternidade. Esse duplo reconhecimento consubstanciase no princípio da dignidade da pessoa humana - consagrado no art. 1ํ, III, da $\mathrm{CF}^{9}$ como fundamento da República Brasileira - bem como do objetivo fundamental de construção de uma sociedade livre, justa e solidária, sem preconceitos de qualquer espécie (CF, art. $3^{\circ}$, I e IV) ${ }^{10}$

Exercer $\mathrm{o}$ direito à dignidade se materializa pela faculdade de escolher $\mathrm{O}$ modo e a pessoa com quem quer se relacionar, bem como o gênero pelo qual quer se identificar, se feminino ou masculino. Com efeito, tal prerrogativa pertence à intimidade e vida privada de cada um, cujo exercício também recebe status de direito fundamental (inciso $X$ do art. 5o da $\mathrm{CF} / 88$ ).

Assim, diante de uma relação homoafetiva entre duas mulheres onde ambas se identificam pelo gênero feminino, não há como afastar o direito das duas de se tornarem mães e, por consequência, de usufruir das garantias que a lei confere à mulher, sob pena de malferimento da dignidade humana e promoção de atos preconceituosos, vedado pelo ordenamento brasileiro.

Cumpre destacar as palavras do Ministro Luiz Fux na ADI o 4.277 dispondo sobre o exercício da dignidade e a faculdade se identificar publicamente:

Permitir ao indivíduo identificar-se publicamente, se assim o quiser, como integrante da família que ele mesmo, no exercício da sua autonomia, logrou constituir, é atender ao princípio da dignidade da pessoa humana; permitir ao homossexual que $o$ faça nas mesmas condições que 0 heterossexual é observar o mesmo respeito e a mesma consideração é atender à igualdade material consagrada na Constituição. (STF, ADI no 0 4.277/DF, Relator Ministro AYRES BRITO, DJE 5/5/2011) (gn) ${ }^{11}$

\footnotetext{
${ }^{9}$ BRASIL, Constituição da República Federativa do. Congresso Nacional, Brasília, 1988.

${ }^{10}$ BRASIL, Constituição da República Federativa do. Congresso Nacional, Brasília, 1988.

${ }^{11}$ BRASIL, STF - SUPREMO TRIBUNAL FEDERAL, ADI no 4.277/DF, Relator Ministro AYRES BRITO, DJE 5/5/2011
} 
Personalidade Acadêmica Homenageada:

Florisbal de Souza Del'Olmo (Professor Convidado - UNICURITIBA)

Consoante ilustre posicionamento, as diferenças entre relações heterossexuais e homossexuais devem ser balizadas pelo princípio da igualdade material consagrada na Constituição Federal.

Segundo, Alexandre de Moraes, o referido princípio se realiza:

[...] na obrigatoriedade ao interprete, basicamente, a autoridade pública, de aplicar a lei e atos normativos de maneira igualitária, sem estabelecimento de diferenciações em razões de sexo, religião, convicções filosóficas ou políticas, raça, classe social ${ }^{12}$

Nesse viés, diante de uma sociedade tão heterogênea, a aplicação da isonomia requer do jurista interpretação integrativa da norma a fim de igualar indivíduos desiguais e permitir a todos o exercício de direitos sem que haja estabelecimento de discriminação de qualquer espécie.

Aplicar o referido princípio à temática sob exame, decorre do reconhecimento de que todas as mulheres são iguais perante a lei, assim como os núcleos familiares formados por casais heterossexuais e homossexuais. Logo, o direito à proteção a família e as garantidas dele decorrentes podem e devem ser exercidos por todas as mulheres/mães que se inserem em ambos os núcleos familiares.

De nada serviria reconhecer o mesmo valor social à família formada por indivíduos do mesmo sexo, se não se estender a ambas as mulheres homoafetivas o direito de se reconhecerem como mãe, caso contrário estar-se-ia reconhecendo parcialmente a entidade familiar formada por duas mulheres, desvirtuando o verdadeiro sentido de família e tornando inócuo o direito de constituição de famílias, a elas estabelecido na ADI no 4.277 .

Dessa forma, a despeito do art. 71-A, § 2으, da Lei ํo 8.213/1991 vedar a concessão de dupla licença maternidade, tal restrição quando aplicável às relações homoafetivas mostra-se contraditória aos preceitos constitucionais, conforme acima

\footnotetext{
${ }^{12}$ MORAES, Alexandre de. Direito constitucional. 30. ed. São Paulo, SP: Atlas, 2014, p. 35.
} 
Personalidade Acadêmica Homenageada:

Florisbal de Souza Del'Olmo (Professor Convidado - UNICURITIBA)

explanado, exigindo do intérprete, uma hermenêutica conforme a Constituição Federal, de modo a garantir a igualdade material a todos os gêneros/sexos.

\section{RESULTADOS OBTIDOS OU ESPERADOS}

A pesquisa alcançou o objetivo de discutir a problemática da dupla licença maternidade na relação homoafetiva formada por duas mulheres, sob o viés do princípio da isonomia material e os preceitos constitucionais da dignidade da pessoa humana, proteção à família e vedação a atos de discriminação de qualquer espécie.

Dessa forma, apurou-se que o estabelecido no art. 71-A, §2- da Lei $\mathrm{n}^{\circ}$ 8.213/1991 se aplicada de modo literal às relações homoafetivas de modo a limitar o direito à licença maternidade a apenas uma das mulheres da relação familiar, malfere direitos humanos constitucionais, além promover tratamento discriminatório, circunstâncias vedadas pelo ordenamento jurídico pátrio e internacional.

\section{TÓPICOS CONCLUSIVOS}

A sociedade vem passando por diversas mudanças sociais, entre elas podese se destacar as novas constituições familiares. Hoje, por meio da ADI ํㅜ 4.277, a Suprema Corte brasileira já pacificou o reconhecimento das relações homoafetivas como entidade familiar, igual, merecendo a mesma proteção constitucional conferida às relações tradicionais, heteroafetivas.

Como instrumento dessa proteção familiar, o ordenamento jurídico garante o direito à licença maternidade, à mãe biológica ou adotante, contudo, veda que tal benefício seja concedido a mais de um segurado.

Nesse sentido, a pesquisa conclui que, em se tratando de relação homoafetiva entre duas mulheres que se identificam como mães, tal vedação legal, por consequência, alija uma das mulheres ao direito de exercer a maternidade de maneira ampla, bem como mitiga parcialmente a concepção de família garantida pela ADI no 4.277, além de promover exclusão social. Logo, a garantia da isonomia 
Personalidade Acadêmica Homenageada:

Florisbal de Souza Del'Olmo (Professor Convidado - UNICURITIBA)

às mulheres homoafetivas perpassa pela perspectiva material, ou seja, desprezar a letra fria da lei para integrar a norma aos preceitos constitucionais, de modo a alcançar a todos o direito e acesso à justiça no mundo prático. 